\title{
Evaluation of different treatment strategies between right-sided and left-sided pneumonectomy for stage I-IIIA non-small cell lung cancer patients
}

\author{
Bo Jia $^{1 \#}$, Qiwen Zheng." ${ }^{2 \#}$, Jianjie Li ${ }^{1 \#}$, Jun Zhao ${ }^{1}$, Meina $\mathrm{Wu}^{1}$, Tongtong An ${ }^{1}$, Yuyan Wang ${ }^{1}$, Minglei Zhuo ${ }^{1}$, \\ Xue Yang ${ }^{1}$, Hanxiao Chen ${ }^{1}$, Yujia Chi ${ }^{1}$, Jingjing Wang ${ }^{1}$, Xiaoyu Zhai ${ }^{1}$, Yuling He ${ }^{1}$, Lingdong Kong ${ }^{1}$, \\ Ziping Wang ${ }^{1}$
}

${ }^{1}$ Key laboratory of Carcinogenesis and Translational Research (Ministry of Education/Beijing), Department of Thoracic Medical Oncology, Peking University Cancer Hospital \& Institute, Beijing, China; ${ }^{2}$ Department of Epidemiology and Biostatistics, School of Public Health, Peking University, Beijing, China

Contributions: (I) Conception and design: B Jia, Z Wang; (II) Administrative support: Z Wang; (III) Provision of study materials or patients: B Jia, Q Zheng, J Li; (IV) Collection and assembly of data: B Jia, J Li; (V) Data analysis and interpretation: Q Zheng; (VI) Manuscript writing: All authors; (VII) Final approval of manuscript: All authors.

"The authors contributed equally to this work and should be considered co-first authors.

Correspondence to: Ziping Wang. Key Laboratory of Carcinogenesis and Translational Research (Ministry of Education/Beijing), Department of Thoracic Medical Oncology, Peking University Cancer Hospital \& Institute, 52 Fucheng Road, Haidian District, Beijing 100142, China.

Email: wangzp2007@126.com.

Background: This study aimed to assess the different survival outcomes of stage I-IIIA non-small cell lung cancer (NSCLC) patients who received right-sided and left-sided pneumonectomy, and to further develop the most appropriate treatment strategies.

Methods: We accessed data from the Surveillance, Epidemiology, and End Results database from the United States for the present study. An innovative propensity score matching analysis was used to minimize the variance between groups.

Results: For 2,683 patients who received pneumonectomy, cancer-specific survival [hazard ratio (HR) $=0.863,95 \%$ confidence interval $(\mathrm{CI}): 0.771$ to $0.965, \mathrm{P}=0.010]$ and overall survival $(\mathrm{OS} ; \mathrm{HR}=0.875,95 \%$ CI: 0.793 to $0.967, \mathrm{P}=0.008$ ) were significantly superior in left-sided pneumonectomy patients compared with right-sided pneumonectomy patients. Cancer-specific survival (HR $=0.847,95 \%$ CI: 0.745 to 0.963 , $\mathrm{P}=0.011)$ and $\mathrm{OS}(\mathrm{HR}=0.858,95 \% \mathrm{CI}: 0.768$ to $0.959, \mathrm{P}=0.007)$ were also significantly longer with leftsided compared to right-sided pneumonectomy after matching analysis of 2,050 patients. Adjuvant therapy could significantly prolong cancer-specific survival (67 versus 51 months, HR =1.314, 95\% CI: 1.093 to 1.579, $\mathrm{P}=0.004$ ) and $\mathrm{OS}$ (46 versus 30 months, $\mathrm{HR}=1.458,95 \% \mathrm{CI}: 1.239$ to $1.715, \mathrm{P}<0.001$ ) among leftsided pneumonectomy patients after the matching procedure, while adjuvant therapy did not increase cancer-specific survival for right-sided pneumonectomy patients (46 versus 42 months, HR =1.112, 95\% CI: 0.933 to $1.325, \mathrm{P}=0.236$ ). Subgroup analysis showed that adjuvant chemotherapy could significantly improve cancer-specific survival and OS for all pneumonectomy patients. However, radiotherapy was associated with worse survival for patients with right-sided pneumonectomy.

Conclusions: Pneumonectomy side can be deemed as an important factor when physicians determine the most optimal treatment strategies.

Keywords: Non-small cell lung cancer (NSCLC); left-side; right-side; pneumonectomy; treatment

Submitted Jan 10, 2021. Accepted for publication Mar 17, 2021.

doi: $10.21037 /$ jtd-21-264

View this article at: http://dx.doi.org/10.21037/jtd-21-264 


\section{Introduction}

Lung cancer has been the most common cancer in China and globally for several decades $(1,2)$. Approximately $75 \%$ to $80 \%$ of lung cancer patients have non-small cell lung cancer (NSCLC) (3). Pneumonectomy can significantly affect quality of life and long-term survival for several reasons. First, pneumonectomy carries the risk of complications, including decreased respiratory function, bronchopleural fistulas, progressive pulmonary hypertension, and elevated right-heart pressure, amongst others $(4,5)$. Second, it has been reported that patients who receive right- or left-sided pneumonectomy may have different prognoses $(6,7)$, and pneumonectomy of the right lung was associated with a higher incidence of mortality and morbidity than that of the left side (8), mainly because the right lung contributes more to overall lung function than the opposite side (9). Third, the anatomical structure, blood supply, and metastatic lymph node routes of the bilateral lungs are not totally identical. Therefore, right- and left-sided pneumonectomy may have distinctive long-term survival, but this problem has not been fully elucidated.

Although adjuvant chemotherapy has been the standard treatment for stage II-IIIA patients with surgery, few studies have examined patients undergoing pneumonectomy. Adjuvant radiotherapy was recommended for stage N2 NSCLC patients especially for those with multi-station mediastinal lymph node metastasis. But the long-term risks and benefits of adjuvant radiotherapy after pneumonectomy remain controversial. It is of great importance to determine the influence of adjuvant therapy on pneumonectomy patients. Therefore, the purpose of this study was to assess whether primary tumor sidedness could influence longterm survival in stage I-IIIA NSCLC patients who received pneumonectomy using a novel and validated PSM approach, and to further develop the best treatment strategies for these patients.

We present the following article in accordance with the STROBE reporting checklist (available at http://dx.doi. org/10.21037/jtd-21-264).

\section{Methods}

\section{Data source}

We accessed data from the Surveillance, Epidemiology, and End Results (SEER) database from the United States for the present study (10). Data codes were recorded by the North American Association of Central Cancer Registries
(NAACCR) (11). The 3rd edition of the International Classification of Diseases for Oncology (ICD-O-3) was used to code primary tumor histology.

\section{Cobort selection}

NSCLC patients aged 18 years or older from 2004 to 2014 were included in this study. Patients with unknown primary tumor location were excluded. All patients received pneumonectomy. The study was exempted from ethical review by the Beijing Cancer Hospital. We obtained the data agreement and data files were downloaded directly from the SEER website (12). A flow chart of patient selection in this study is shown in Figure S1.

\section{Statistical analysis}

Patients were categorized into left-sided and right-sided pneumonectomy. We used the chi-square test or Fisher's exact test between groups to perform univariate analysis. A propensity score was constructed to reduce potential bias. A multivariate logistic regression model was constructed, including variables such as age, gender, race, year of diagnosis, tumor stage, $\mathrm{T}$ stage, $\mathrm{N}$ stage, original site, histology, number of lymph node dissections, radiotherapy, and chemotherapy. Matching (1:1) across the 2 groups was achieved with a 0.2 -width caliper of the standard deviation of the logit of the propensity score. To evaluate the matching performance, baseline variables were compared using the McNemar's test between the matched groups, and a difference between -0.1 and 0.1 is generally considered negligible for the calculation of standardized differences.

We assessed overall survival (OS) and cancer-specific survival using Kaplan-Meier curves in the matched groups. Relationships between pneumonectomy laterality and OS or cancer-specific survival were evaluated using a Cox regression model stratified by matched pairs.

R software (version 3.3.3; http://www.r-project.org) was used for statistical analysis. The significance levels were all two-sided, with statistical significance set at 0.05 .

The study was conducted in accordance with the Declaration of Helsinki (as revised in 2013).

\section{Results}

\section{Patient characteristics}

In this study, 2,683 stage I-IIIA NSCLC patients who 
received pneumonectomy between 2004 and 2014 were included. Of these patients, 1,150 patients received rightsided pneumonectomy and 1,533 patients received leftsided pneumonectomy. Patient characteristics between the 2 groups are illustrated in Table 1. More patients with rightsided pneumonectomy had stage I NSCLC $(\mathrm{P}=0.006)$, N0 $(\mathrm{P}=0.005)$, had an overlapping lesion $(\mathrm{P}=0.007)$, and had adenocarcinomas $(\mathrm{P}<0.001)$. Fewer patients with right-sided pneumonectomy received chemotherapy $(\mathrm{P}=0.025)$.

\section{Survival}

The median follow-up was 25 months. Cancer-specific survival [hazard ratio $(\mathrm{HR})=0.863,95 \%$ confidence interval (CI): 0.771 to $0.965, \mathrm{P}=0.010]$ and $\mathrm{OS}(\mathrm{HR}=0.875,95 \%$ CI: 0.793 to $0.967, \mathrm{P}=0.008$ ) were significantly superior with left-sided pneumonectomy compared to rightsided pneumonectomy, with 5 -year OS rates of $36.4 \%$ (95\% CI: $33.4 \%$ to $39.6 \%$ ) and $40.2 \%$ (95\% CI: $37.5 \%$ to $43.1 \%$ ) for patients who received right-sided and leftsided pneumonectomy, respectively (Figure S2). After multivariate adjustment, differences were also significant between left-sided and right-sided pneumonectomy both in cancer-specific survival (HR $=0.836,95 \% \mathrm{CI}: 0.746$ to 0.937 , $\mathrm{P}=0.002)$ and $\mathrm{OS}(\mathrm{HR}=0.841,95 \% \mathrm{CI}: 0.760$ to 0.929 , $\mathrm{P}<0.001$; Table 2).

Patients who had a clinical $\mathrm{T}$ stage of $\mathrm{T} 2$ or $\mathrm{T} 3$ $(\mathrm{P}<0.001)$, a clinical $\mathrm{N}$ stage of $\mathrm{N} 1(\mathrm{P}=0.036)$ or $\mathrm{N} 2$ $(\mathrm{P}=0.007)$, had large cell carcinoma $(\mathrm{P}=0.004)$, were diagnosed before $2008(\mathrm{P}<0.001)$, were diagnosed older than $40(\mathrm{P}<0.042)$, were male $(\mathrm{P}<0.019)$, did not receive chemotherapy $(\mathrm{P}<0.001)$, and received beam radiotherapy $(\mathrm{P}=0.009)$ or other radiotherapy $(\mathrm{P}=0.008)$ were associated with significantly poorer cancer-specific survival in the multivariate analysis (Table 2).

After propensity score matching, the propensity scores for NSCLC patients who received right-sided and left-sided pneumonectomy were both $0.566 \pm 0.073$ ( $\mathrm{P}=0.833$; Figure $\mathrm{S} 3$ ). After the matching procedure, 2,050 patients were included for further analysis, with 1,025 patients in both groups (Table 1). Cancer-specific survival (HR $=0.847,95 \%$ CI: 0.745 to $0.963, \mathrm{P}=0.011$ ) and $\mathrm{OS}$ (HR $=0.858,95 \% \mathrm{CI}: 0.768$ to $0.959, \mathrm{P}=0.007$ ) were significantly longer with left-sided compared to right-sided pneumonectomy (Figure 1).

\section{Adjuvant therapy}

We further analyzed the impact of adjuvant therapy on survival. Among the left-sided pneumonectomy patients, patients who received adjuvant therapy $(\mathrm{N}=860)$ had significantly prolonged cancer-specific survival $(65$ versus 44 months, $\mathrm{HR}=1.319,95 \% \mathrm{CI}: 1.134$ to 1.534 , $\mathrm{P}<0.001)$ and $\mathrm{OS}(47$ versus 28 months, $\mathrm{HR}=1.489,95 \%$ CI: 1.305 to $1.701, \mathrm{P}<0.001)$ than patients who received pneumonectomy alone ( $\mathrm{N}=673$; Figure S4). Among the right-sided pneumonectomy patients, patients who received adjuvant therapy $(\mathrm{N}=582)$ had significantly prolonged OS (36 versus 25 months, HR $=1.335$, 95\% CI: 1.152 to $1.548, \mathrm{P}<0.001)$ but no significant improvement in cancerspecific survival (46 versus 46 months, $\mathrm{HR}=1.056,95 \%$ CI: 0.893 to $1.249, \mathrm{P}=0.522$ ) compared to patients who received pneumonectomy alone $(\mathrm{N}=568$; Figure $\mathrm{S} 5)$. After the matching procedure, cancer-specific survival (67 versus 51 months, $\mathrm{HR}=1.314,95 \% \mathrm{CI}: 1.093$ to $1.579, \mathrm{P}=0.004$ ) and OS (46 versus 30 months, HR $=1.458,95 \%$ CI: 1.239 to $1.715, \mathrm{P}<0.001)$ were also significantly longer for patients who received adjuvant therapy $(\mathrm{N}=581)$ compared with patients who received left-sided pneumonectomy alone ( $\mathrm{N}=444$; Figure 2). Patients who received rightsided pneumonectomy and adjuvant therapy $(\mathrm{N}=525)$ did not achieve superior cancer-specific survival (46 versus 42 months, $\mathrm{HR}=1.112,95 \% \mathrm{CI}: 0.933$ to $1.325, \mathrm{P}=0.236$ ) compared to patients who received pneumonectomy alone $(\mathrm{N}=500)$, although adjuvant therapy could improve OS (36 versus 25 months, $\mathrm{HR}=1.362,95 \% \mathrm{CI}: 1.165$ to 1.592 , $\mathrm{P}<0.001$; Figure 3).

Subgroup analysis showed that adjuvant therapy could significantly improve cancer-specific survival and OS for stage II and stage IIIA patients with pneumonectomy of either side $(\mathrm{P}<0.05)$. Adjuvant therapy was not associated with prolonged cancer-specific survival $(\mathrm{P}=0.687)$ and OS $(\mathrm{P}=0.177)$ for stage I patients with right-sided pneumonectomy. Although adjuvant therapy could increase OS for stage I patents with pneumonectomy of the left lung $(\mathrm{P}=0.014)$, no differences in cancer-specific survival were observed $(\mathrm{P}=0.273)$.

Subgroup analysis also showed that adjuvant chemotherapy could significantly improve cancerspecific survival and OS for all pneumonectomy patients. However, radiotherapy was associated with worse OS and cancer-specific survival for patients with rightsided pneumonectomy. The median OS for right-sided pneumonectomy patients who received chemotherapy alone, radiotherapy alone, chemoradiotherapy, and no adjuvant therapy were $54,12,28$, and 25 months, respectively $(\mathrm{P}<0.001)$. Additionally, the median cancer- 
Table 1 Comparison of baseline characteristics between right-sided and left-sided pneumonectomy patients in the original and matched datasets

\begin{tabular}{|c|c|c|c|c|c|c|c|c|}
\hline Variable & \multicolumn{4}{|c|}{ Original dataset } & \multicolumn{4}{|c|}{ Matched dataset } \\
\hline Up to 40 years & $17(1.5)$ & $13(0.8)$ & 0.059 & & $11(1.1)$ & $12(1.2)$ & -0.009 & \\
\hline 41 to 69 years & $862(75.0)$ & $1146(74.8)$ & -0.005 & & 775 (75.6) & 788 (76.9) & -0.0 & \\
\hline Gender & & & & 0.217 & & & & 0.882 \\
\hline Male & $792(68.9)$ & $1020(66.5)$ & -0.050 & & $707(69.0)$ & $703(68.6)$ & 0.008 & \\
\hline Female & $358(31.1)$ & $513(33.5)$ & 0.050 & & $318(31.0)$ & $322(31.4)$ & -0.008 & \\
\hline Asian & $53(4.6)$ & $54(3.5)$ & -0.055 & & $37(3.6)$ & $39(3.8)$ & -0.010 & \\
\hline Other/unknown & $10(0.9)$ & $23(1.5)$ & 0.058 & & $9(0.9)$ & $8(0.8)$ & 0.011 & \\
\hline Year of diagnosis & & & & 0.694 & & & & 0.196 \\
\hline 2004-2007 & $510(44.3)$ & $655(42.7)$ & -0.033 & & $453(44.2)$ & $429(41.9)$ & 0.047 & \\
\hline 2008-2011 & $400(34.8)$ & $545(35.6)$ & 0.016 & & 359 (35.0) & $381(37.2)$ & -0.045 & \\
\hline 2012-2014 & 240 (20.9) & $333(21.7)$ & 0.021 & & $213(20.8)$ & $215(21.0)$ & -0.005 & \\
\hline Tumor stage $\mathrm{e}^{\ddagger}$ & & & & 0.006 & & & & 0.148 \\
\hline Stage I & 389 (33.8) & 437 (28.5) & -0.115 & & $330(32.2)$ & $336(32.8)$ & -0.012 & \\
\hline T3 & 214 (18.6) & $271(17.7)$ & -0.024 & & $193(18.8)$ & $195(19.0)$ & -0.005 & \\
\hline $\mathrm{TX}$ & $4(0.3)$ & $1(0.1)$ & -0.062 & & - & - & - & \\
\hline Clinical N stage & & & & 0.005 & & & & 0.507 \\
\hline No & 466 (40.5) & $533(34.8)$ & -0.119 & & $400(39.0)$ & $401(39.1)$ & -0.002 & \\
\hline $\mathrm{N} 1$ & $412(35.8)$ & $631(41.2)$ & 0.109 & & $380(37.1)$ & 355 (34.6) & 0.051 & \\
\hline $\mathrm{N} 2$ & $272(23.7)$ & $369(24.1)$ & 0.010 & & 245 (23.9) & 269 (26.2) & -0.054 & \\
\hline Original site & & & & 0.007 & & & & 0.544 \\
\hline Lung lobe & $892(77.6)$ & 1250 (81.5) & 0.098 & & 817 (79.7) & 792 (77.3) & 0.059 & \\
\hline Main bronchus & $102(8.9)$ & $140(9.1)$ & 0.009 & & $91(8.9)$ & $113(11.0)$ & -0.072 & \\
\hline $\begin{array}{l}\text { Overlapping } \\
\text { lesion of lung }\end{array}$ & $121(10.5)$ & $108(7.0)$ & -0.123 & & $93(9.1)$ & $91(8.9)$ & 0.007 & \\
\hline NOS & $35(3.0)$ & $35(2.3)$ & -0.047 & & $24(2.3)$ & $29(2.8)$ & -0.031 & \\
\hline
\end{tabular}

Table 1 (continued) 
Table 1 (continued)

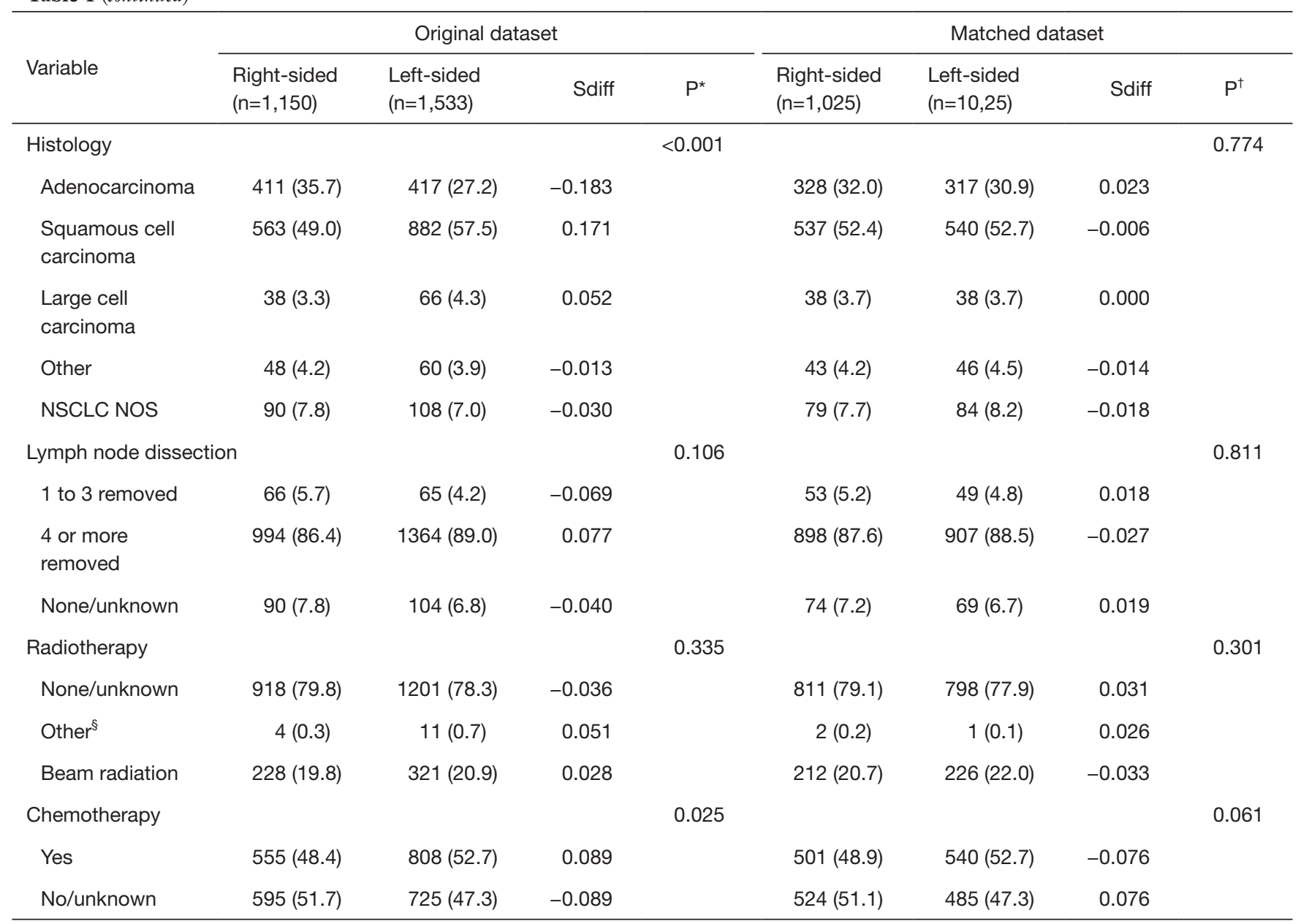

${ }^{*}, \mathrm{P}$ value for chi-square test or Fisher's exact test; ${ }^{\dagger}, \mathrm{P}$ value for McNemar's test or general McNemar's test; ${ }^{\ddagger}$, The 6 th Edition of the AJCC Cancer Staging Manual; ${ }^{\S}$, isotope, implant, or the combination. AJCC, American Joint Committee on Cancer; Sdiff, standardized difference.

specific survival for right-sided pneumonectomy patients who received chemotherapy alone, radiotherapy alone, chemoradiotherapy, and no adjuvant therapy were 68,13 , 32 , and 46 months, respectively $(\mathrm{P}<0.001)$. Radiotherapy did not significantly improve $O S$ and cancer-specific survival for left-sided pneumonectomy patients either. The median OS for left-sided pneumonectomy patients who received chemotherapy alone, radiotherapy alone, chemoradiotherapy, and no adjuvant therapy were 59, 33, 36 , and 28 months, respectively $(\mathrm{P}<0.001)$. The median cancer-specific survival for left-sided pneumonectomy patients who received chemotherapy alone, radiotherapy alone, chemoradiotherapy, and no adjuvant therapy were 94 months, 44 months, 44 months, and 44 months, respectively $(\mathrm{P}<0.001)$.

OS was favorable for left-sided pneumonectomy across clinical subgroups, including stage II or IIIA, squamous cell carcinoma, and those who received chemoradiotherapy or radiotherapy (Figure 4).

\section{Discussion}

To our knowledge, this is the largest and the first population-based study using a novel propensity score matching analysis to assess the influence of pneumonectomy side on the survival outcomes of NSCLC patients. This study indicated that pneumonectomy side may be an important factor when physicians determine the most 


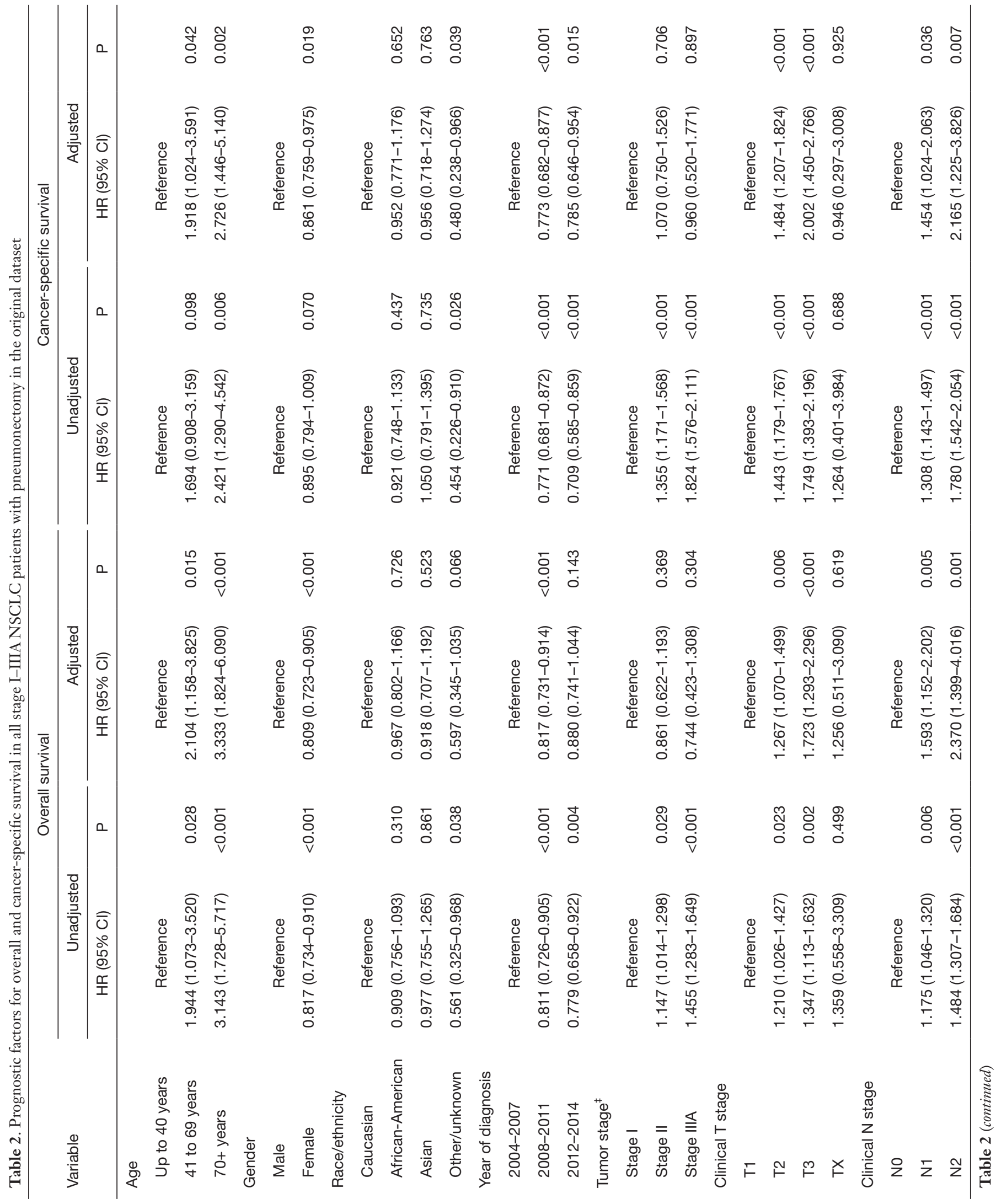




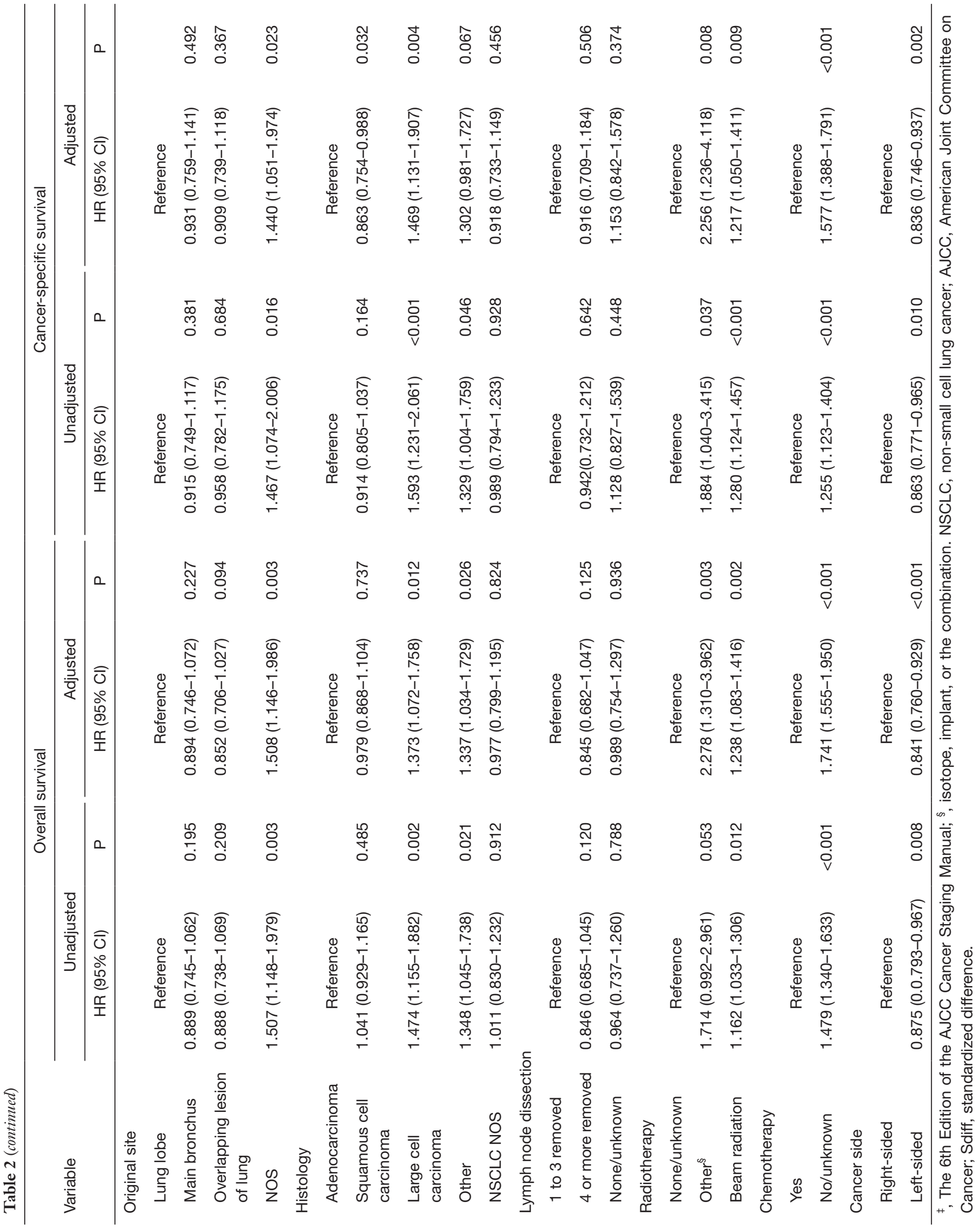



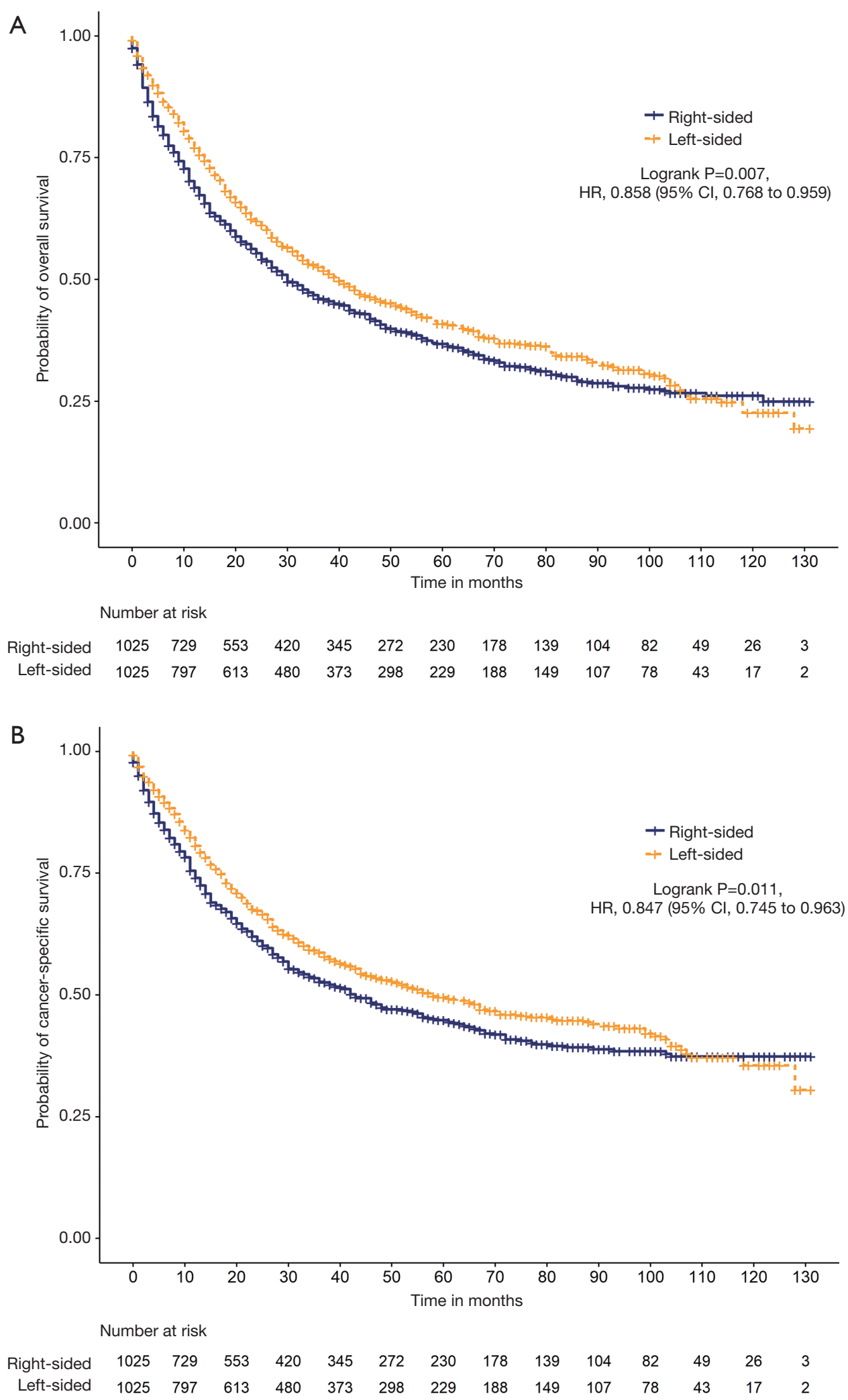

Figure 1 Overall survival and cancer-specific survival among stage I-IIIA non-small cell lung cancer (NSCLC) patients with pneumonectomy in the matched dataset. (A) Overall Survival. (B) Cancer-specific survival. 

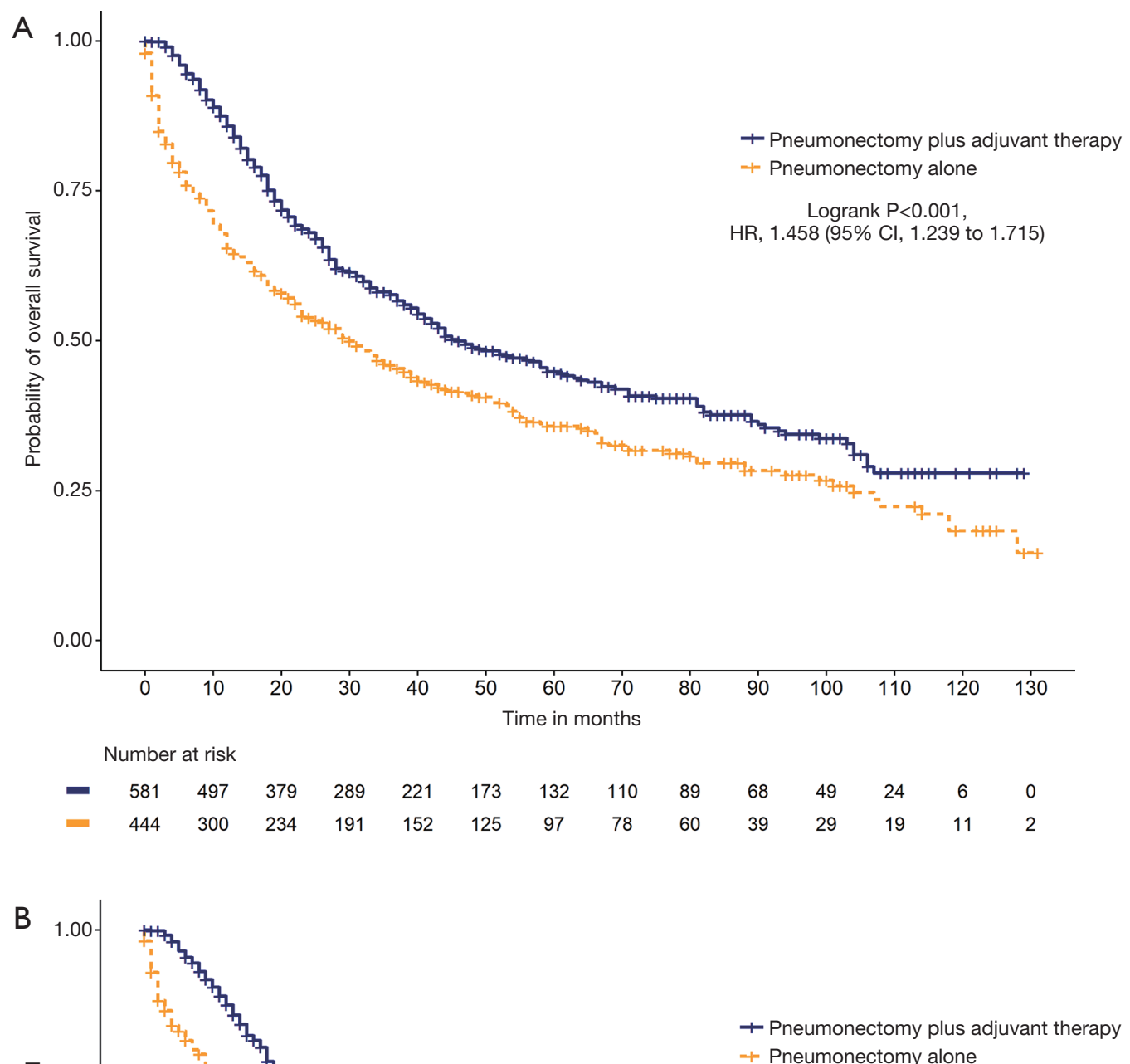
+ Pneumonectomy alone

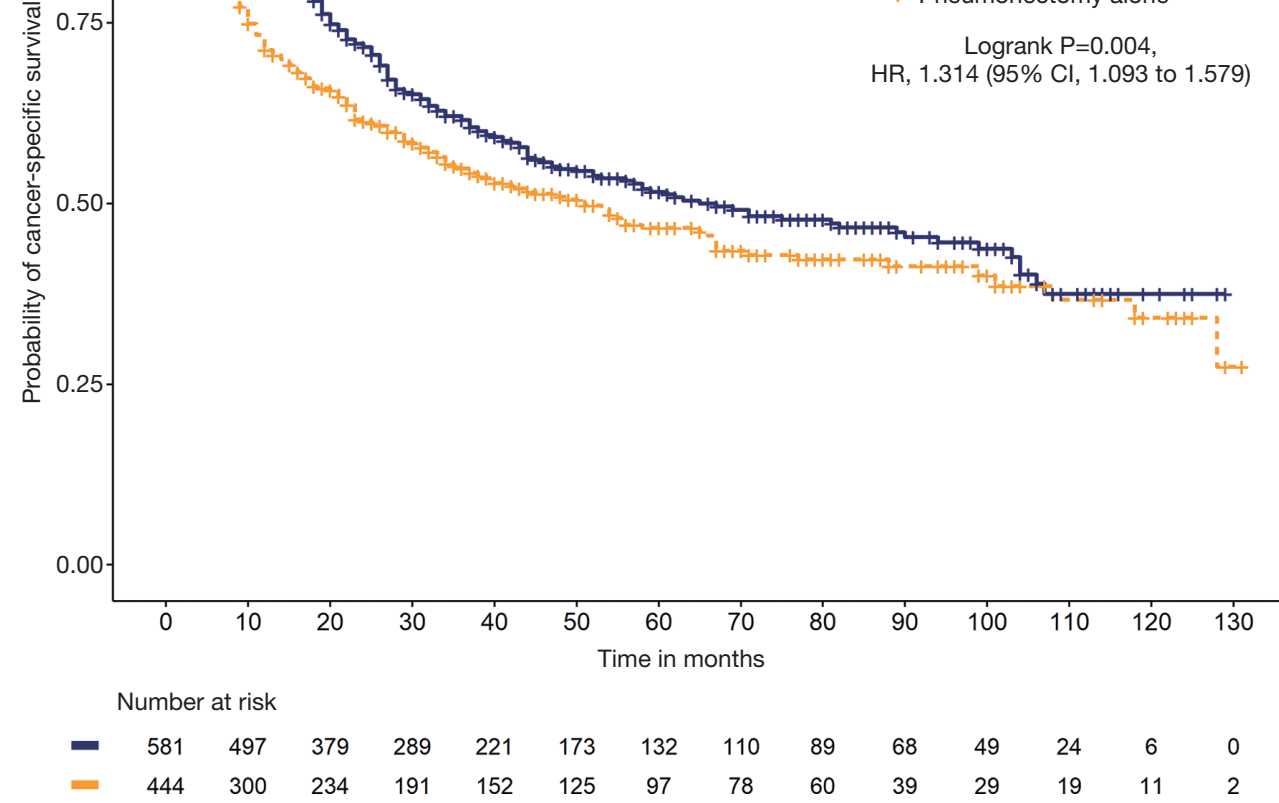

Figure 2 Overall survival and cancer-specific survival among stage I-IIIA non-small cell lung cancer (NSCLC) patients with left-sided pneumonectomy in the matched dataset. (A) Overall Survival. (B) Cancer-specific survival. 

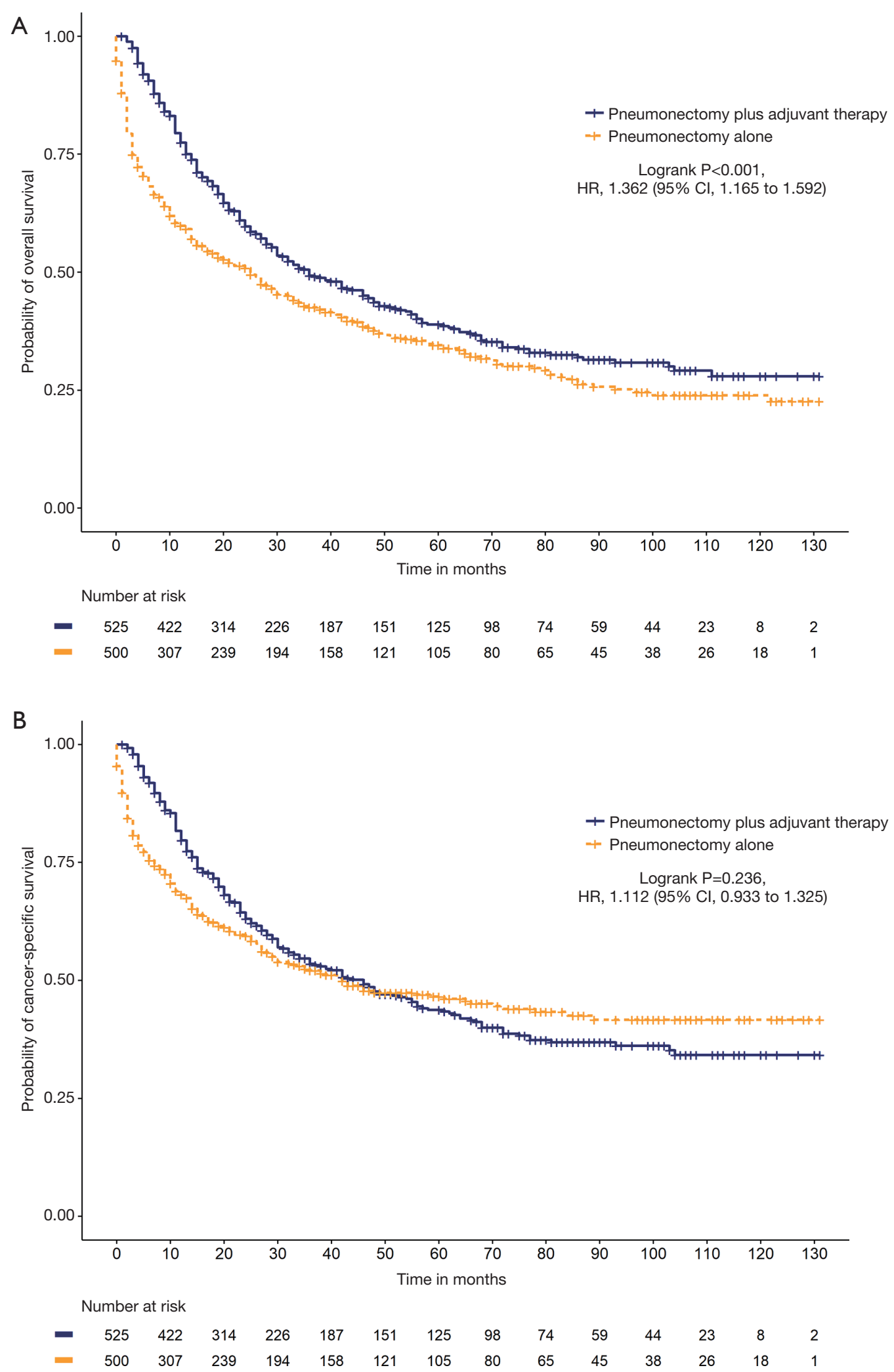

Figure 3 Overall survival and cancer-specific survival among stage I-IIIA non-small cell lung cancer (NSCLC) patients with right-sided pneumonectomy in the matched dataset. (A) Overall survival. (B) Cancer-specific survival. 


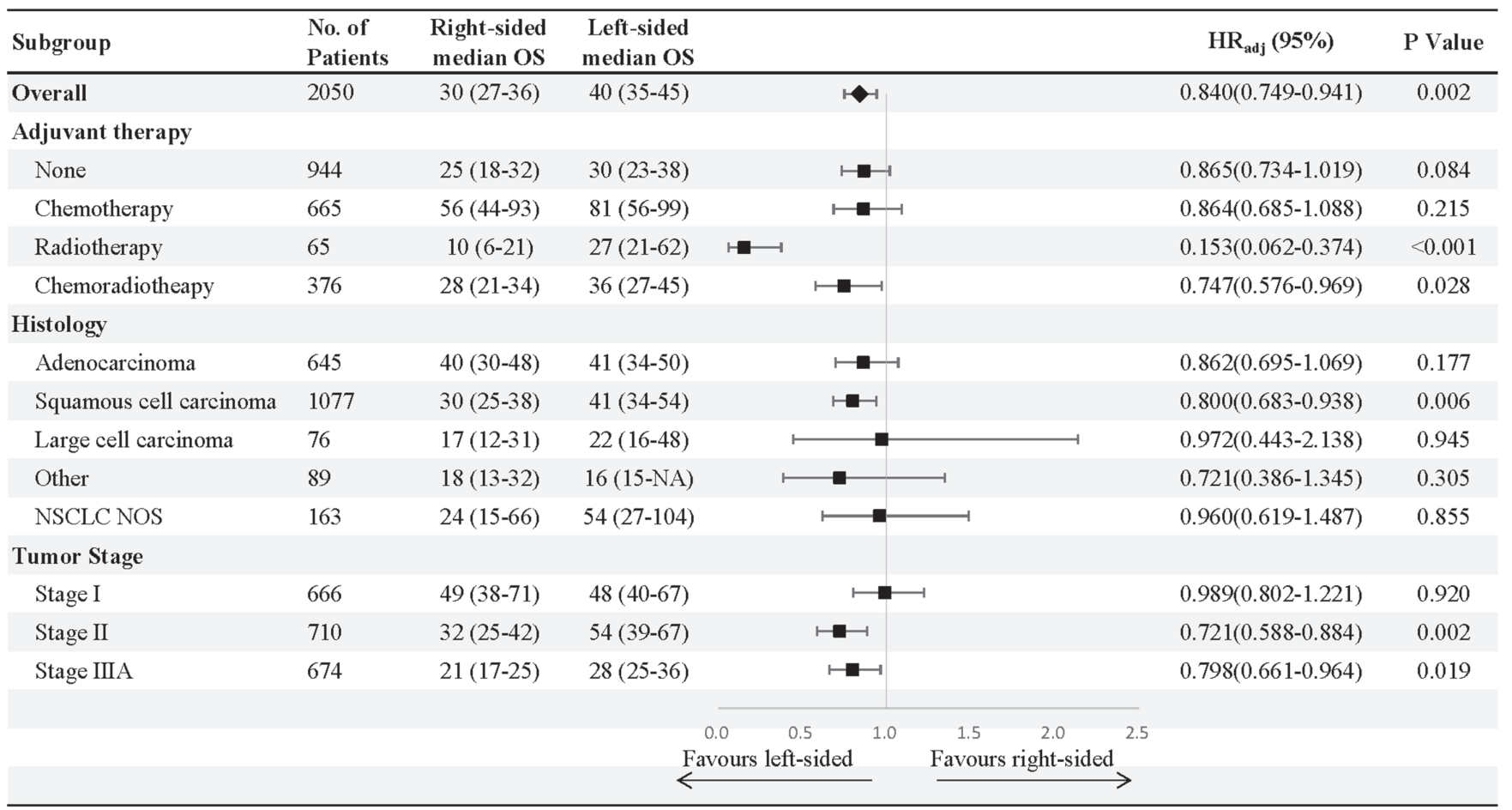

Figure 4 Overall survival by subgroup among stage I-IIIA non-small cell lung cancer (NSCLC) patients with right-sided and left-sided pneumonectomy in the matched dataset.

optimal treatment strategies.

Lung cancer has been the most commonly diagnosed cancer and the leading cause of cancer death. In recent years, several studies have shown that the survival outcomes between right- and left-sided pneumonectomy are different $(6,8)$. One previous study showed that the perioperative death incidence was higher for patients with right-sided pneumonectomy (8). It has also been demonstrated that right pneumonectomy was associated with poorer survival outcomes and more postoperative complications $(6,13)$. The results in our study were consistent with previous studies, indicating that OS and cancer-specific survival were significantly longer with leftsided pneumonectomy versus right-sided pneumonectomy. Several reasons might contribute to this phenomenon. First, the right lung is thought to be more vital for lung function. Therefore, pneumonectomy of the right lung might lead to greater loss of alveolar volume, pulmonary reserve reduction, and ultimately a decrease in respiratory function. Second, pneumonectomy is disposed to increased pulmonary artery pressure and can even cause right heart failure. The major complications were more likely to affect the long-time survival of right-side pneumonectomy. Third, lung cancers located across the 2 sides have different skipping metastasis routes to mediastinal lymph nodes. Finally, the anatomical structures differ between the right and left lung. Therefore, pneumonectomy side could be a fundamental prognostic factor, and patients receiving rightsided pneumonectomy may need closer follow up for the risk of perioperative complications.

Previous studies showed the occurrence of bronchopleural fistula after surgery, more advanced pathological stage, and older age were the poor prognostic factors for patients with pneumonectomy $(14,15)$. The poor prognostic factors found in our study included patients with a clinical $\mathrm{T}$ stage of $\mathrm{T} 2$ or $\mathrm{T} 3$, a clinical $\mathrm{N}$ stage of $\mathrm{N} 1$ or $\mathrm{N} 2$, large cell carcinoma, diagnosed before 2008, diagnostic age older than 40, male, did not receive chemotherapy, and received beam radiotherapy or other radiotherapy in the multivariate analysis. Besides, pneumonectomy should be carefully selected only in patients with the potential benefits overweigh the surgical risk. It is worth noting that patients who did not receive chemotherapy, or received beam radiotherapy or other radiotherapy had worse cancer- 
specific survival, which indicated that chemotherapy was essential for patients with pneumonectomy, while the role of radiotherapy was controversial.

The 2015 World Health Organization (WHO) classification of tumors of the lung had numerous important changes and the most significant change was a new emphasis on genetic studies for advanced lung cancer patients. Epidermal growth factor receptor (EGFR) mutation was more likely to occur in patients who were Asian, female, non-smokers. Anaplastic lymphoma kinase (ALK) rearrangement occurred more likely in patients who were younger, women and non-smokers. But for patients with surgery, chemotherapy and radiotherapy were still the predominant treatment. The relationship between the above gene status and the overall survival for lung cancer patients received chemotherapy is still controversial. It is imperative to investigate the impact of adjuvant therapy on patients with pneumonectomy. One previous study showed that radiotherapy dose was significantly related to a higher incidence of death owing to cardiopulmonary disease (16). Another study indicated that radiotherapy might cause higher death rates due to respiratory disease (5). However, several other studies showed that the mortality difference was not significant with regards to perioperative chemotherapy and radiotherapy $(17,18)$. Our study demonstrated that adjuvant therapy could significantly prolong survival for patients who received left-sided pneumonectomy, but did not improve survival for patients with right-sided pneumonectomy. We also found that adjuvant chemotherapy was associated with significantly improved survival for both left- and right-sided pneumonectomy patients. One previous study showed that preoperative chemotherapy was associated with severe pulmonary disease. Therefore the most appropriate treatment sequence might be pneumonectomy followed by adjuvant chemotherapy. However, radiotherapy did not show survival benefits for patients with pneumonectomy, and even worsened the prognosis of right-sided pneumonectomy patients. The complications in patients with pneumonectomy can cause cardiopulmonary insufficiency, and adjuvant radiotherapy may cause further respiratory function deterioration. This might be the main cause of death for patients with pneumonectomy. Moreover, the results of our study demonstrated that adjuvant therapy was not essential for stage I patients with pneumonectomy, which was also in accordance with previous studies.

There were some limitations in this study. First, we used the 6th edition of the American Joint Committee on Cancer staging manual rather than the 7 th edition. This is because we selected patients in the SEER database from 2004 to 2014 and all patients had staging records based on the 6th edition in the database. If we chose the 7 th version, there would be many missing values. Furthermore, there were no significant differences between the 6 th and 7 th edition stages, which did not have a considerable effect on the study results. Second, some variables, such as surgical quality or R0 margin, were not actually available in the SEER database, and we were unable to analyze these data (19). Therefore a large sample study with more information should be conducted to further verify our conclusion. Third, Uniportal video-assisted thoracic surgery (UniVATS) technique was a new surgical method with less invasion. The efficacy of UniVATS pneumonectomy for NSCLC patients needed further study. But this information was not recorded in database.

\section{Conclusions}

Right-sided pneumonectomy was associated with worse survival compared to left-sided pneumonectomy. Adjuvant therapy could significantly prolong survival among leftsided pneumonectomy patients, while adjuvant therapy did not increase cancer-specific survival for patients with rightsided pneumonectomy. Adjuvant chemotherapy showed significant benefits for patients who received either left- or right-sided pneumonectomy, but radiotherapy worsened prognosis for right-sided pneumonectomy patients. This study suggests that pneumonectomy side can be deemed as an important factor when physicians determine the most optimal treatment strategies.

\section{Acknowledgments}

We acknowledge the SEER*Stat team for providing patient information. This manuscript has been released as a preprint at [Research Square], [https://www.researchsquare. com/article/rs-64392/v1].

Funding: This research was funded by Science Foundation of Peking University Cancer Hospital (1802); Capital Clinical Characteristics and Application Research (Z181100001718104); Beijing Excellent Talent Cultivation Subsidy Young Backbone Individual Project (2018000021469G264). 


\section{Footnote}

Reporting Checklist: The authors have completed the STROBE reporting checklist. Available at http://dx.doi. org/10.21037/jtd-21-264

Conflicts of Interest: All authors have completed the ICMJE uniform disclosure form (available at http://dx.doi. org/10.21037/jtd-21-264). The authors have no conflicts of interest to declare.

Ethical Statement: The authors are accountable for all aspects of the work in ensuring that questions related to the accuracy or integrity of any part of the work are appropriately investigated and resolved. The study was conducted in accordance with the Declaration of Helsinki (as revised in 2013).

Open Access Statement: This is an Open Access article distributed in accordance with the Creative Commons Attribution-NonCommercial-NoDerivs 4.0 International License (CC BY-NC-ND 4.0), which permits the noncommercial replication and distribution of the article with the strict proviso that no changes or edits are made and the original work is properly cited (including links to both the formal publication through the relevant DOI and the license). See: https://creativecommons.org/licenses/by-nc-nd/4.0/.

\section{References}

1. Siegel RL, Miller KD, Jemal A. Cancer statistics, 2016. CA Cancer J Clin 2016;66:7-30.

2. Chen $\mathrm{W}$, Zheng R, Baade PD, et al. Cancer statistics in China, 2015. CA Cancer J Clin 2016;66:115-32.

3. Travis WD. Pathology of lung cancer. Clin Chest Med 2011;32:669-92.

4. Ferguson MK, Karrison T. Does pneumonectomy for lung cancer adversely influence long-term survival? J Thorac Cardiovasc Surg 2000;119:440-8.

5. Kim DJ, Lee JG, Lee CY, et al. Long-term survival following pneumonectomy for non-small cell lung cancer: clinical implications for follow-up care. Chest 2007;132:178-84.

6. Simon C, Moreno N, Penalver R, et al. The side of pneumonectomy influences long-term survival in stage I and II non-small cell lung cancer. Ann Thorac Surg 2007;84:952-8.
7. Kim AW, Faber LP, Warren WH, et al. Pneumonectomy after chemoradiation therapy for non-small cell lung cancer: does "side" really matter? Ann Thorac Surg 2009;88:937-43; discussion 944.

8. Martin J, Ginsberg RJ, Abolhoda A, et al. Morbidity and mortality after neoadjuvant therapy for lung cancer: the risks of right pneumonectomy. Ann Thorac Surg 2001;72:1149-54.

9. Kopec SE, Irwin RS, Umali-Torres CB, et al. The postpneumonectomy state. Chest 1998;114:1158-84.

10. Surveillance, Epidemiology, and End Results (SEER) Program (www.seer. cancer.gov) Research Data (19732014), National Cancer Institute, DCCPS,Surveillance Research Program, Surveillance Systems Branch, released March 2017, based on the March 2017 submission. www. seer.cancer.gov. Accessed 23 March 2017.

11. Wingo PA, Jamison PM, Hiatt RA, et al. Building the infrastructure for nationwide cancer surveillance and control--a comparison between the National Program of Cancer Registries (NPCR) and the Surveillance, Epidemiology, and End Results (SEER) Program (United States). Cancer Causes Control 2003;14:175-93.

12. Surveillance, Epidemiology, and End Results Program. Data use agreement for the 1973-2014 SEER Research Data File. Available online: https://seer.cancer.gov/data/ access.html\#agreement. Accessed Mar 23, 2017.

13. Kalathiya RJ, Davenport D, Saha SP. Long-term survival after pneumonectomy for non-small-cell lung cancer. Asian Cardiovasc Thorac Ann 2013;21:574-81.

14. Speicher PJ, Ganapathi AM, Englum BR, et al. Survival in the elderly after pneumonectomy for early-stage nonsmall cell lung cancer: a comparison with nonoperative management. J Am Coll Surg 2014;218:439-49.

15. Alexiou C, Beggs D, Rogers ML, et al. Pneumonectomy for non-small cell lung cancer: predictors of operative mortality and survival. Eur J Cardiothorac Surg 2001;20:476-80.

16. Machtay M, Lee JH, Shrager JB, et al. Risk of death from intercurrent disease is not excessively increased by modern postoperative radiotherapy for high-risk resected nonsmall-cell lung carcinoma. J Clin Oncol 2001;19:3912-7.

17. Margaritora S, Cesario A, Cusumano G, et al.

Pneumonectomy with and without induction chemoradiotherapy for non-small cell lung cancer: short and long-term results from a single centre. Eur Rev Med Pharmacol Sci 2013;17:29-40. 
18. Gudbjartsson T, Gyllstedt E, Pikwer A, et al. Early surgical results after pneumonectomy for non-small cell lung cancer are not affected by preoperative radiotherapy and chemotherapy. Ann Thorac Surg 2008;86:376-82.

19. Jia B, Zheng Q, Li J, et al. Evaluation of Different Treatment Strategies Between Right-sided and Left-sided
Pneumonectomy for Stage I-IIIA Non-small Cell Lung Cancer Patients. Research Square 2020. doi: 10.21203/ rs.3.rs-64392/v1.

(English Language Editor: C. Betlazar-Maseh)

Cite this article as: Jia B, Zheng Q, Li J, Zhao J, Wu M, An T, Wang Y, Zhuo M, Yang X, Chen H, Chi Y, Wang J, Zhai X, He Y, Kong L, Wang Z. Evaluation of different treatment strategies between right-sided and left-sided pneumonectomy for stage I-IIIA non-small cell lung cancer patients. J Thorac Dis 2021;13(3):1799-1812. doi: 10.21037/jtd-21-264. 


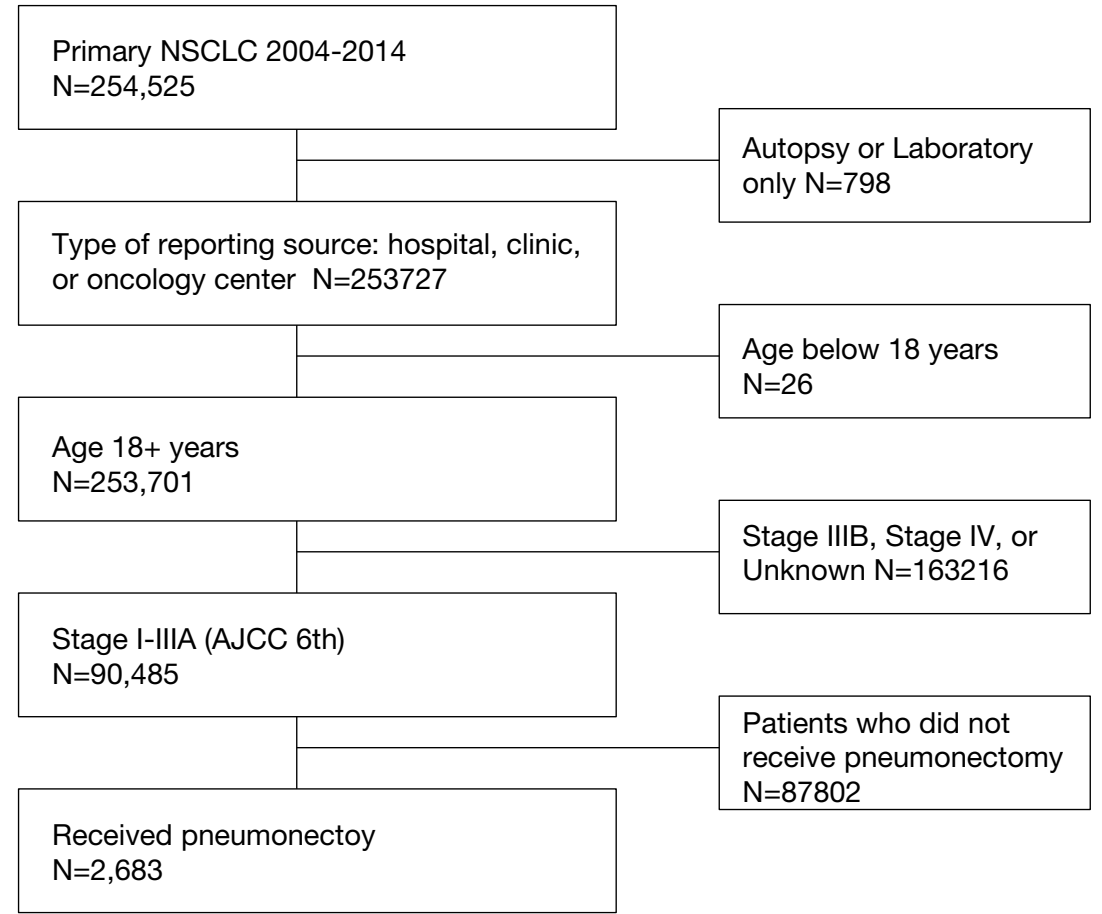

Figure S1 Flow chart of patients' selection.
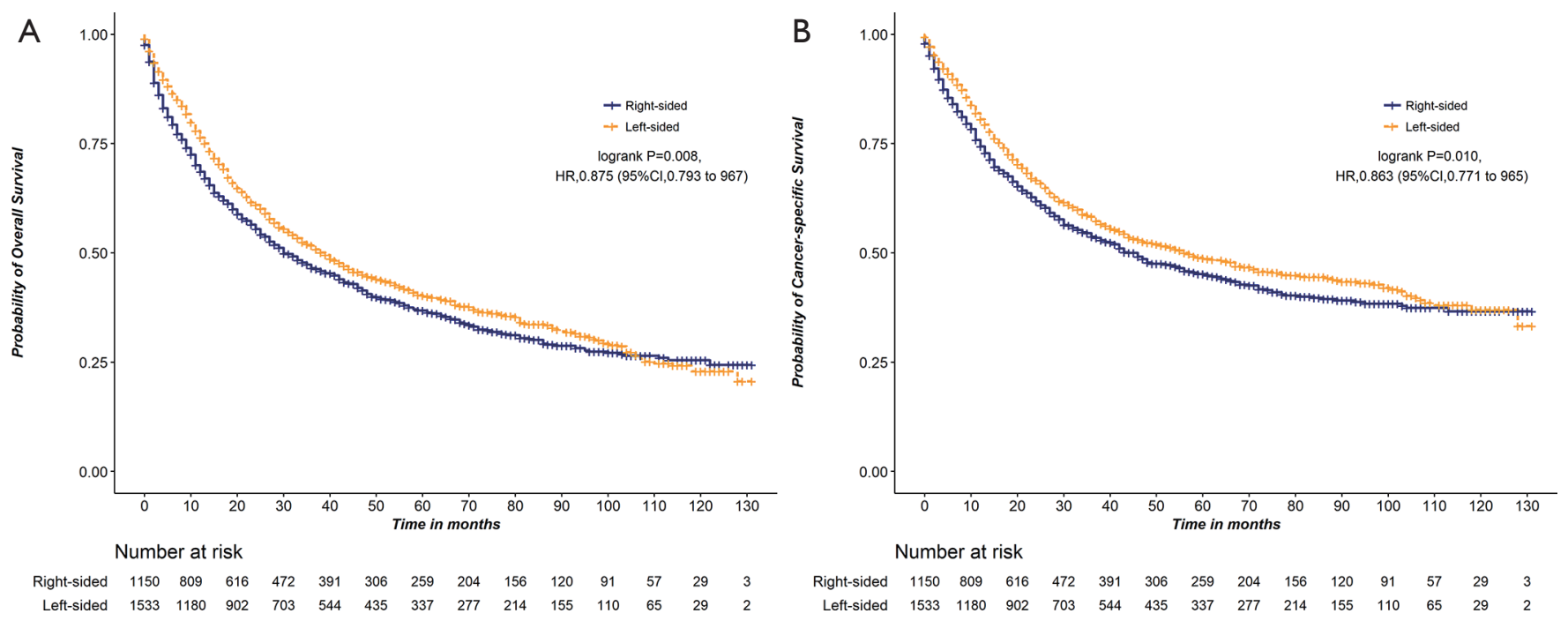

Figure S2 Overall survival and Cancer-specific survival among stage I-IIIA NSCLC patients with pneumonectomy in the original data set. (A) overall survival. (B) Cancer-specific Survival. 
A

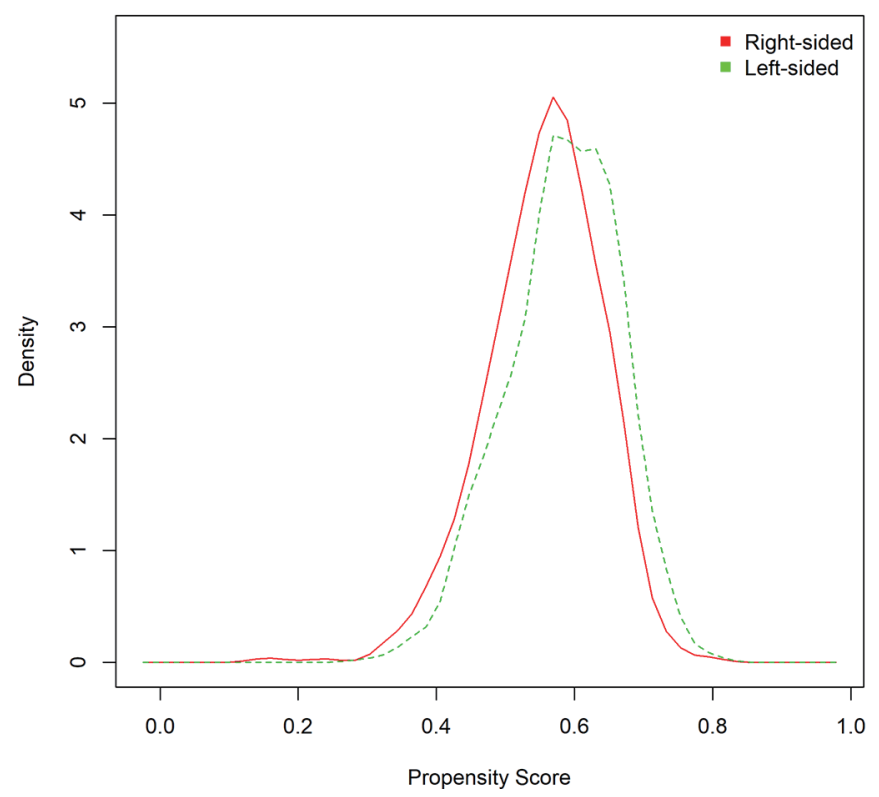

B

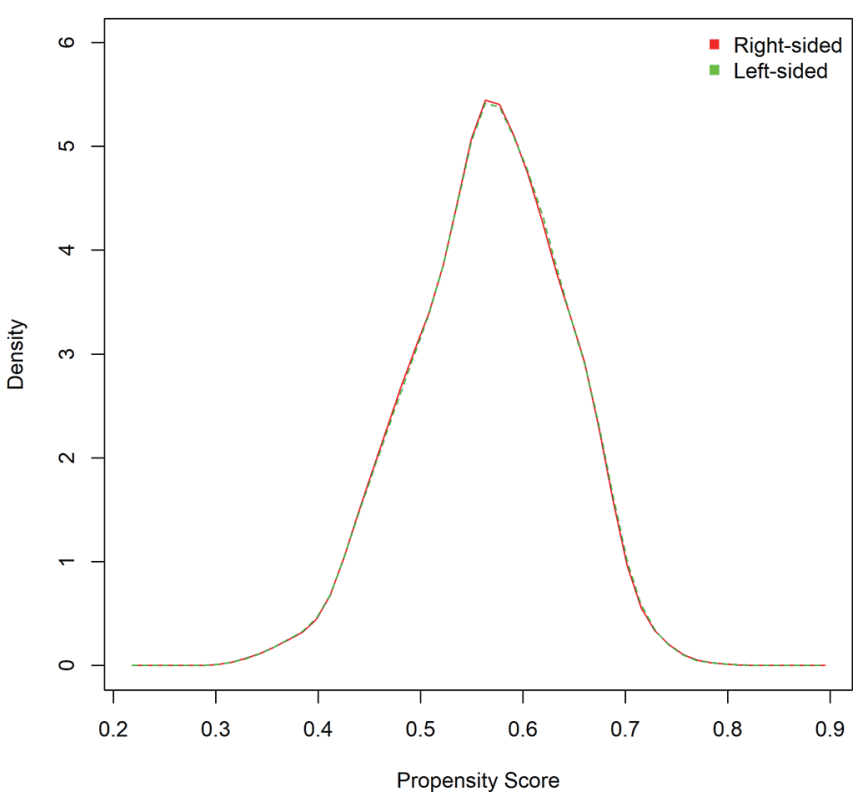

Figure S3 Propensity score distributions (A) before matching, and (B) after matching.

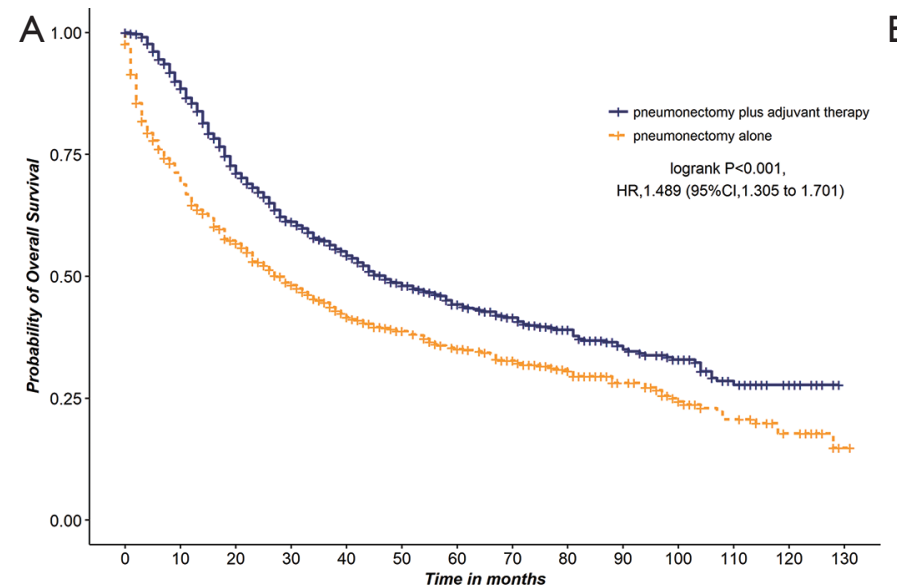

Number at risk

$\begin{array}{lllllllllllllll}\text { - } & 860 & 729 & 554 & 425 & 323 & 255 & 192 & 160 & 125 & 95 & 70 & 38 & 14 & 0 \\ - & 673 & 451 & 348 & 278 & 221 & 180 & 145 & 117 & 89 & 60 & 40 & 27 & 15 & 2\end{array}$

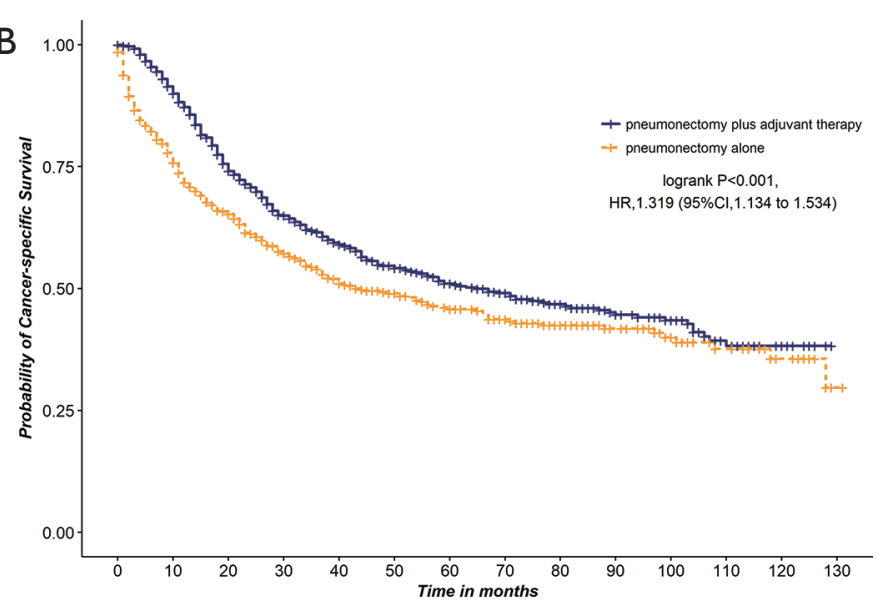

Number at risk

$\begin{array}{lllllllllllllll}\text { - } & 860 & 729 & 554 & 425 & 323 & 255 & 192 & 160 & 125 & 95 & 70 & 38 & 14 & 0 \\ \text { - } & 673 & 451 & 348 & 278 & 221 & 180 & 145 & 117 & 89 & 60 & 40 & 27 & 15 & 2\end{array}$

Figure S4 Overall survival and cancer-specific survival among stage I-IIIA NSCLC patients with pneumonectomy in left-sided lung in the original data set. (A) Overall survival. (B) Cancer-specific survival.

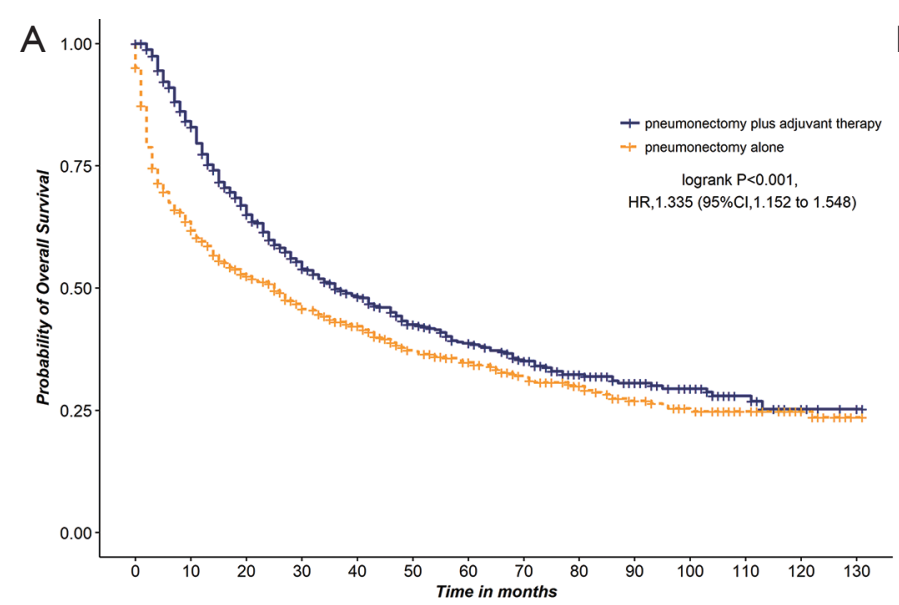

Number at risk

- \begin{tabular}{llllllllllllll}
582 & 465 & 346 & 252 & 208 & 165 & 138 & 110 & 80 & 64 & 47 & 25 & 8 & 2 \\
\hline
\end{tabular}

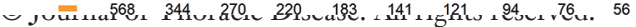

Figure S5 Overall survival and cancer-specific survival among stage I-IIIA NSCLC patients with pneumonectomy in right-sided lung in the original data set. (A) Overall survival. (B) Cancer-specific survival.

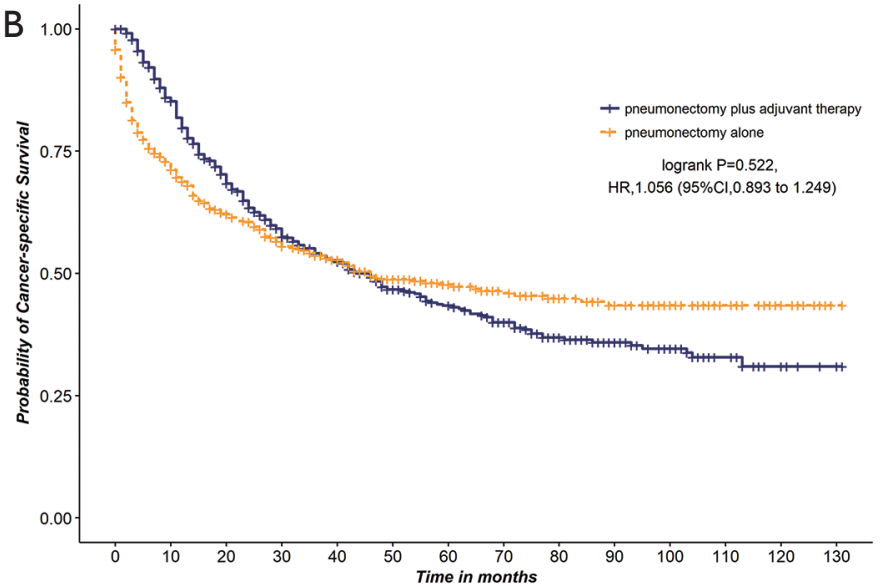

Number at risk

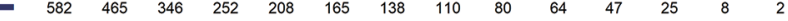

$\begin{array}{ccccccccccccccc}- & 582 & 465 & 346 & 252 & 208 & 165 & 138 & 110 & 80 & 64 & 47 & 25 & 8 & 2 \\ - & 568 & 344 & 270 & 220 & 183 & 141 & 121 & 94 & 76 & 56 & 44 & 37 & 21 & 1\end{array}$ 